\section{Photoperiod Sometimes Influences Common Bacterial Blight Disease of Common Beans}

\author{
Mohamed F. Mohamed ${ }^{1}$ and Dermot P. Coyne ${ }^{2}$ \\ Department of Horticulture, University of Nebraska, Lincoln, NE 68583-0724
}

Additional index words. Xanthomonas campestris pv. phaseoli, Phaseolus vulgaris, rapid leaf chlorosis, hypersensitive reaction, germplasm, flowering, flower bud removal

\begin{abstract}
Common bacterial blight, incited by Xanthomonas campestris pv. phaseoli (Smith) Dye (Xcp), is a serious disease of common beans (Phaseolus vulgaris L.). Three experiments were conducted twice in growth chambers at $26 \pm 1 \mathrm{C}$ under short $(10$ hours light/14 hours dark) and long ( 16 hours light/8 hours dark) photoperiods to determine the influence of these photoperiods, flower bud removal, pod development, and pre- and postinoculation photoperiods on the reaction of common beans to Xcp. In one test, 'PC-50' (susceptible; S) flowered earlier and was more susceptible to $X c p$ under the short photoperiod than under the long photoperiod. BAC-6 (resistant; R) flowered at the same time under both photoperiods but developed rapid leaf chlorosis (RLC) (hypersensitive reaction) under long photoperiods. Flowering and disease reactions to $\mathrm{Xcp}$ by $\mathrm{XAN}-159$ (R) were similar under both photoperiods. In a second test, daily removal of flower buds of 'PC-50' decreased its susceptibility to $X c p$ under the short photoperiod. RLC of inoculated leaves of BAC-6 occurred during flowering and pod development under both photoperiods. XAN-159 expressed a high level of resistance to $X c p$ but showed RLC at later pod development stages. In a third test, the disease reaction of ' $\mathrm{PC}-50$ ' was affected by the particular photoperiod applied post-inoculation but was not influenced by the photoperiod applied before inoculation with $X c p$. The implications of these results in breeding beans for resistance to $X c p$ are discussed.
\end{abstract}

Common bacterial blight disease of common bean caused by Xanthomonas campestris pv. phaseoli $(X c p)$, is a serious disease affecting seed yield and quality (Hedges, 1928; Yoshii, 1980). Disease management strategies include sanitation, crop rotation, and use of disease-free seed. There is no effective chemical control for common blight disease (M.L. Schuster and D.P. Coyne, Univ. of Nebraska, unpublished data). Breeding for disease resistance is recommended as an effective control strategy (Coyne and Schuster, 1983).

Using resistance is problematical because it can be modified by geographic region, specifically photoperiod, and also because patho-

Received for publication 8 Aug. 1994. Accepted for publication 23 Jan. 1995. We thank Anne K. Vidaver and Patricia Lambrecht, Dept. of Plant Pathology, for a $X c p$ bacterial isolate $\left(\mathrm{V}_{4} \mathrm{~S}_{1}\right)$, and Kent Eskridge, Dept. of Biometry, Univ. of Nebraska, Lincoln, for statistical advice. We gratefully acknowledge the Title XII Bean/Cowpea Collaborative Research Support Program Project, Univ. of Nebraska, Univ. of Puerto Rico, and Dominican Republic under USAID Contract DNA-1310-G-SS-6008-00 and also ARD, UNL, NE Research project no. 20-036. Published as paper no. 10805, Journal Series, Nebraska Agricultural Research Division. The cost of publishing this paper was defrayed in part by the payment of page charges. Under postal regulations, this paper therefore must be hereby marked advertisement solely to indicate this fact.

${ }^{1}$ Former Visiting Scientist. Currently, Associate Professor, Dept. of Horticulture, Faculty of Agriculture, Univ. of Assiut, Assiut, Egypt.

${ }^{2}$ George Holmes Regents Professor. gens can vary by region. Webster et al. (1983) found that bean germplasm resistant to $X c p$ in northern latitudes matured early under short photoperiods in the tropics, and this difference in maturity, relative to adapted lines, led to eventual expression of a relatively susceptible reaction to Xcp. Arnaud-Santana et al. (1993) also reported that photoperiod affected the reaction of bean germplasm to $X c p$. This information on the effect of environment on the reaction of bean germplasm to $X c p$ has important implications for breeders in developing more effective resistance to Xcp. Breeders need to know how common-blight-resistant bean lines will react to the $X c p$ pathogen in response to latitudes. More information is needed on the effect of photoperiod on bean flowering and pod development in relation to the $X c p$ reaction and also on the influence of photoperiod before inoculation of the plants with $X c p$ compared to the photoperiod during the post-inoculation stage. To our knowledge, the latter comparison has not been investigated. Therefore, our objectives were to determine the influence of photoperiod; flower bud removal; pod development under two photoperiods; and the photoperiods themselves when used before or after inoculation with $X c p$ on the disease reaction of resistant and susceptible beans.

\section{Materials and Methods}

Cultivar effect (Expt. 1). The effect of photoperiods on the reaction of beans to Xcp was investigated in a split-plot arrangement with two photoperiods [10 h light/14 h dark
(10/14) and 16h light/8 h dark (16/8)] as whole plots in a completely randomized design. The subplot treatments were three bean cultivars/ lines (BAC-6, 'PC-50', and XAN-159) distributed in a randomized complete-block design. The experiment was conducted twice. BAC-6, developed by Mohan (1981), is an indeterminate black-seeded bean line with resistance to $X c p$ and rust. 'PC-50' (developed by Freddy Saladin Garcia, Centro sur de Desarrollo Agropecuario, San Cristobal, Dominican Republic; personal communication), is a high-yielding, determinate, red, mottleseeded bean cultivar derived from a single plant selection made in the Pompadour Checa landrace, and it is susceptible to $X c p$ and resistant to many rust races. XAN-159, a breeding line derived from a complex cross involving $P$. vulgaris lines $\times$ P. acutifolius A. Gray and selected by McElroy (1985), is a determinate line with grey mottled seed and is a cultivar highly resistant to $X c p$. We selected these cultivars/lines because of the prior knowledge of the resistance of BAC-6 and XAN-159 and the differential response of 'PC-50' to $X c p$ in tropic and temperate regions (ArnaudSantana et al., 1993).

Two growth chambers were used for each photoperiod. Each growth chamber contained two replicates of each of the three bean cultivars/lines. Two $15-\mathrm{cm}$ clay pots (1.8 liters) were used for each bean cultivar/line per replication within a growth chamber. Two seeds were planted ( 8 Nov. 1992) per pot containing a mixture of equal parts by volume of soil (Sharpsburg silty clay loam), sand, sphagnum peat, and vermiculite.

The mean light intensity from six incandescent $100-\mathrm{W}$ bulbs and 16 fluorescent 176 $\mathrm{W}$ tubes was $0.28 \mu \mathrm{mol} \cdot \mathrm{m}^{-2} \cdot \mathrm{s}^{-1}$ at the pot rim (76 $\mathrm{cm}$ below the lights). The growth chambers were maintained at $26 \pm 1 \mathrm{C}$. Starting 10 days after planting, plants were fertilized

Table 1. Common blight disease lesions and number of days to flowering of three bean entries (means of two replications in time) under two photoperiods in growth chambers.

\begin{tabular}{|c|c|c|c|c|}
\hline \multirow[b]{3}{*}{ Cultivar/line } & \multirow{2}{*}{\multicolumn{2}{|c|}{$\begin{array}{c}\text { Lesion } \\
\text { expansion }(\mathrm{cm})^{\mathrm{z}} \\
\text { Photoperiod } \\
(\mathrm{h}) \\
\end{array}$}} & \multirow{2}{*}{\multicolumn{2}{|c|}{$\begin{array}{c}\text { Days to } \\
\text { flowering } \\
\text { Photoperiod } \\
\text { (h) }\end{array}$}} \\
\hline & & & & \\
\hline & 10 & 16 & 10 & 16 \\
\hline PC-50 & 2.6 & 1.3 & 25 & 34 \\
\hline XAN-159 & 0.1 & 0.1 & 25 & 27 \\
\hline BAC- $6^{y}$ & 0.2 & $\operatorname{RLC}^{\mathrm{x}}$ & 38 & 38 \\
\hline (1) $\operatorname{LSD}_{0.05}{ }^{\mathrm{w}}$ & \multicolumn{2}{|c|}{0.6} & \\
\hline (2) $\operatorname{LSD}_{0.05}$ & \multicolumn{2}{|c|}{0.4} & \multicolumn{2}{|c|}{1} \\
\hline
\end{tabular}

${ }^{\text {zLeaves were inoculated } 17 \text { days after planting using }}$ the razor blade method. The lesion size was measured as the distance from inoculated site to the lesion edge 12 days after inoculation.

$\mathrm{BAC}-6$ was not included in the analysis of variance for lesion size because of the rapid leaf chlorosis reaction of leaves under the 16-h photoperiod (see text).

${ }^{x} \mathrm{RLC}=$ rapid leaf chlorosis; leaves developed RLC 3 to 4 days after inoculation and then abscised. ${ }^{\mathrm{w}} \mathrm{LSD}$ compared 1) lesion expansion (except for BAC 6 ) and days to flowering within entries between photoperiod treatments and 2) lesion expansion and days to flowering of entries within a photoperiod. 
weekly with $200 \mathrm{ppm} \mathrm{N}$ (0.4 liter/pot) from a $9 \mathrm{~N}-3.5 \mathrm{P}-16.5 \mathrm{~K}$ fertilizer containing trace elements. Plants were watered as needed.

A stock culture of $X c p$ strain $\mathrm{V}_{4} \mathrm{~S}_{1}$ (formerly DR-12) was stored in $40 \%$ glycerol at $-20 \mathrm{C}$. The $\mathrm{V}_{4} \mathrm{~S}_{1}$ strain was cultured for $48 \mathrm{~h}$ in petri dishes containing MXP semi-selective medium for $X c p$ at $27 \mathrm{C}$ in an incubation room (Claflin et al., 1987). The Xcp concentration in the suspension used for inoculation was $1.5 \times$ $10^{7}$ colony-forming units (cfu) $/ \mathrm{ml}$ (in $12.5 \mathrm{~mm}$ potassium phosphate buffer, $\mathrm{pH}$ 7.1, containing $10 \mathrm{~mm}$ magnesium sulphate).

The first trifoliolate leaves (two-thirds to fully expanded) of 17-day-old plants were inoculated with $X c p$ using the razor blade method (Pastor-Corrales et al., 1981). Two of the three leaflets per trifoliolate were inoculated; the third leaflet was inoculated only with a phosphate buffer solution (control). Lesion sizes were recorded 12 days later by measuring the distance (in centimeters) that the lesion had progressed from the inoculation site. The number of days to flower also was recorded for each bean entry.

Flower bud removal and stage of pod development effects (Expt. 2). The effect of flower bud removal and pod development stage of beans was investigated in a split-plot arrangement, with whole plots being photoperiod treatments as in Expt. 1. The subplots were two plant treatments, conducted twice, for each of the cultivars/lines used in Expt. 1 within each photoperiod treatment at the inoculation time. The experiment was conducted two times. Flower buds were removed daily from 'PC-50' and BAC-6 entries in one treatment; control plants of these entries were allowed to flower and develop pods. 'PC-50' was inoculated with $X c p$ strain $\mathrm{V}_{4} \mathrm{~S}_{1}$ at 36 days and BAC- 6 at 45 days after planting (25 Sept. 1992) due to the different flowering periods of these entries. Because the flowering of XAN159 in Expt. 1 did not affect the reaction to $X c p$, only the effect of pod development stage ( 2 to $3 \mathrm{~cm}$ vs. 5 to $7 \mathrm{~cm}$ pod length) on the reaction to $X c p$ was investigated. The first and second trifoliolate leaves of the three bean entries were inoculated with the $X c p$ as described in Expt. 1. The growth chamber conditions, seed planting, plant maintenance, inoculation method, and common blight disease evaluation used in Expt. 2 were similar to those in Expt. 1.

Timing of inoculation (Expt. 3). The effect of the two photoperiods before and after inoculation of 'PC-50' on the reaction to Xcp was investigated in growth chambers. A randomized complete-block design within each of the two photoperiod treatments used in Expt. 1 was run twice (first planting, 12 Aug. 1992; second planting, 25 Jan. 1993).

The plant treatments under 10/14 were 1) $10 \mathrm{~h}$ light/14 h dark continuously and 2) plants maintained under $16 \mathrm{~h}$ light $/ 8 \mathrm{~h}$ dark for 3 weeks, then transferred to $10 \mathrm{~h}$ light/14 h dark just before $X c p$ inoculation. For this purpose, one growth chamber was maintained at $10 \mathrm{~h}$ light $/ 14 \mathrm{~h}$ dark and another at $16 \mathrm{~h}$ light $/ 8 \mathrm{~h}$ dark. At the time of inoculation with $X c p$ strain $\mathrm{V}_{4} \mathrm{~S}_{1}$, the 16-h light/8-h dark photoperiod was changed to a $10 \mathrm{~h}$ light/14 $\mathrm{h}$ dark, and the corresponding plants were exchanged between the two growth chambers. Thus, each chamber contained two groups of plants (i.e., plants continuously grown under $10 / 14 \mathrm{~h}$ and those receiving $16 / 8 \mathrm{~h}$ for 3 weeks before the inoculation). The growth chambers were maintained at $26 \pm 1 \mathrm{C}$.

The plant treatments under $16 / 8$ were 1) 16 $\mathrm{h}$ light/8 h darkness continuously, and 2) plants that had received 10-h light/14-h dark treatment for 3 weeks were moved to $16 \mathrm{~h}$ light/ 8 $\mathrm{h}$ darkness just before inoculation.

The first fully expanded trifoliolate leaves of plants in all treatments were inoculated with $X c p$ suspension (same concentration as in Expt. 1) using the multiple needle method (MNM; florists' frog) (Andrus, 1948). The MNM inoculation was used because of greater ease of operating and recording the amount of disease on the leaves. The percentage of the leaf area with common blight disease symptoms 12 days after inoculation and the number of days to flowering were recorded.

Data in all experiments were subjected to analysis of variance using the general linear model procedure of the SAS computer statistical package (SAS Institute, 1982).

\section{Results}

Cultivar effect (Expt. 1). Photoperiod and bean cultivar/lines interacted in respect to disease lesions produced and number of days to flowering. 'PC-50' was more susceptible to $X c p$ and flowered earlier under the 10-h than under the 16-h photoperiod (Table 1). The number of days to flowering for BAC-6 and XAN-159 were similar under both photoperiods. The limited size of leaf disease lesions of the resistant XAN-159 was similar under the two photoperiods. The lesion size of the resistant BAC-6 under the 10-h photoperiod was similar to that of XAN-159. Under the 16-h photoperiod, many leaves of BAC-6 developed rapid leaf chlorosis (RLC) 3 to 4 days after inoculation and abscised $\left(\mathrm{X}^{2}=21.9, P<\right.$ 0.001 ). This phenomenon is considered to be a hypersensitive response of BAC- 6 under the long photoperiod.

Flower bud removal and pod development effects (Expt. 2). Photoperiod $\times$ plant treatments were significant for 'PC-50' and XAN159 (Table 2). The lesions of the flowering 'PC-50' plants, inoculated 36 days after planting, had expanded more under a 10-h than under a 16-h photoperiod (Table 2). However,

Table 2. Leaf lesions from common blight disease of bean entries as affected by photoperiod, flower bud removal, and pod size (means of two replications in time) in growth chambers.

\begin{tabular}{|c|c|c|}
\hline \multirow{3}{*}{$\begin{array}{l}\text { Cultivar or line/ } \\
\text { Flower bud or pod treatments }\end{array}$} & \multicolumn{2}{|c|}{ Lesion expansion $(\mathrm{cm})^{\mathrm{z}}$} \\
\hline & \multicolumn{2}{|c|}{ Photoperiod (h) } \\
\hline & 10 & 16 \\
\hline \multicolumn{3}{|c|}{ PC-50 (inoculated 36 days after planting) } \\
\hline Flower buds removed & 3.7 & 2.1 \\
\hline Flowering and bearing pods & 9.9 & 3.2 \\
\hline (1) $\operatorname{LSD}_{0.05}{ }^{y}$ & \multicolumn{2}{|c|}{3.2} \\
\hline (2) $\operatorname{LSD}_{0.05}$ & \multicolumn{2}{|c|}{1.8} \\
\hline \multicolumn{3}{|c|}{ Xan-159 (inoculated 45 days after planting) } \\
\hline Pods 2 to $3 \mathrm{~cm}$ long & 0.3 & 0.3 \\
\hline Pods 5 to $7 \mathrm{~cm}$ long & 1.1 & $\mathrm{RLC}^{\mathrm{x}}$ \\
\hline (1) $\operatorname{LSD}_{0.05}{ }^{y}$ & \multicolumn{2}{|c|}{0.9} \\
\hline (2) $\operatorname{LSD}_{0.05}$ & \multicolumn{2}{|c|}{0.7} \\
\hline \multicolumn{3}{|c|}{ BAC-6 (inoculated 45 days after planting) } \\
\hline Flower buds removed & RLC & RLC \\
\hline Flowering and bearing pods & RLC & RLC \\
\hline
\end{tabular}

${ }^{2}$ The razor blade method of inoculation was used; lesions were measured [distance (in centimeters) of lesion edge area from inoculated site] 12 days after inoculation.

${ }^{y_{L S D}}$ compared the lesion expansion 1) within flowering or pod stage of development between photoperiods, and 2) for flowering or pod treatments within a photoperiod, except for XAN-159 (pods 5 to $7 \mathrm{~cm}$ long) because of rapid leaf chlorosis under a 16-h photoperiod.

${ }^{\mathrm{x}} \mathrm{RLC}=$ rapid leaf chlorosis (hypersensitive reaction).

Table 3. Influence of photoperiod treatments after inoculation with Xanthomonas campestris pv. phaseoli on the percentage of leaf area with common blight symptoms (means of two replications in time) in leaves of 'PC-50' plants induced to flower under two pre-inoculation photoperiods in growth chambers.

\begin{tabular}{|c|c|c|c|c|}
\hline \multirow{3}{*}{$\begin{array}{l}\text { Pre-inoculation } \\
\text { photoperiod (h) }\end{array}$} & \multicolumn{4}{|c|}{ Post-inoculation photoperiod } \\
\hline & \multicolumn{2}{|c|}{$10^{2}$} & \multicolumn{2}{|c|}{$16^{2}$} \\
\hline & Diseased area $(\%)^{y}$ & Days to flowering & $\overline{\text { Diseased area }(\%)^{\mathrm{y}}}$ & Days to flowering \\
\hline 10 , continuous & $98(9.9)^{x}$ & 25 & & \\
\hline 16 , first 3 weeks & $96(9.8)$ & 32 & & \\
\hline $\mathrm{LSD}_{0.05}$ & NS & 1 & & \\
\hline 16 , continuous & & & $69(8.3)$ & 33 \\
\hline 10 , first 3 weeks & & & $68(8.3)$ & 25 \\
\hline $\mathrm{LSD}_{0.05}$ & & & NS & 2 \\
\hline
\end{tabular}

${ }^{{ }^{Z}}$ Separate studies were conducted for each photoperiod regime.

y Leaves were inoculated 21 days after planting with a multiple needle.

${ }^{x}$ Square-root-transformed data presented in parenthesis.

${ }^{\text {Ns Nonsignificant. }}$ 
the lesions of 'PC-50' were similar in length under the two photoperiods when flower buds were removed (Table 2). XAN-159 was highly resistant to $X c p$ under both photoperiods when inoculated in the early pod development stage ( 2 to $3 \mathrm{~cm}$ in length) (Table 2). However, lesions of same-age XAN-159 plants but with longer pods $(5$ to $7 \mathrm{~cm}$ ) were longer than those on plants with shorter pods under the 10-h photoperiod (Table 2). All inoculated leaves of XAN-159 developed RLC and abscised under 16/8 h. RLC and defoliation occurred on inoculated BAC-6 plants under both flowering and both photoperiod treatments; thus, lesion size was not measured (Table 2).

Timing of inoculation (Expt. 3). Pre-inoculation photoperiod had a significant effect on the number of days to flowering of 'PC-50' (Table 3). 'PC-50' flowered later under the long photoperiod than under the short photoperiod. However, the percentage of the inoculated area of 'PC-50' with common blight symptoms were similar within each of the two post-inoculation photoperiod treatments, whether the pre-inoculation photoperiod was short or long, indicating that the photoperiod prevailing during the post-inoculation phase was the primary influence on the amount of disease present (Table 3).

\section{Discussion}

Aggour et al. (1989) reported that the degree of RLC was affected by cultivar, method of inoculation, and $X c p$ concentration. They found less RLC with the razor blade method of inoculation than with the MNM and with $10^{6}$ $\mathrm{cfu} / \mathrm{ml}$ than with $10^{8} \mathrm{cfu} / \mathrm{ml}$. However, they did not investigate the influence of photoperiod on RLC. RLC occurred on all plants of BAC-6 under short and long photoperiods when inoculated 45 days (flowering stage) after planting but only on plants under long photoperiods inoculated 17 days (vegetative stage) after planting. XAN-159 only showed RLC on plants with more-developed pods, with no RLC occurring on plants with lessdeveloped pods. The different sizes of the lesions of 'PC-50' under short and long photoperiods agrees with Arnaud-Santana et al.'s (1993) findings on this cultivar.

There was no significant difference between disease lesion expansion of leaves of 'PC-50' when flower buds were removed, but lesion expansion between normal flowering plants depended on photoperiod, indicating an effect of flower development on disease lesion expansion. 'PC-50' plants under both photoperiods were the same age and at the same reproductive stage. There was no significant difference in leaf disease lesion expansion of 'PC-50' plants with flower buds removed and flowering plants with pods under long photoperiod, but lesion expansion differed for plants receiving these treatments under short photoperiod. This difference suggests that not only differences in plant vigor or in maturity may be involved, but also that differences in the amounts of assimilates in leaves may affect disease reactions. Webster et al. (1983) explained that the differential response of two field-grown bean lines to $X c p$ under short and long photoperiods in the tropics was related to differences in plant vigor and maturity induced by these regimes. Andrus (1948) also found that plant vigor affected the bean reaction to $X c p$ but did not explore the influence of photoperiod.

The amount of disease on 'PC-50' plants was similar within each separate post-inoculation photoperiod treatment regardless of the number of days required to flowering, which in turn had been induced by pre-inoculation photoperiod treatments. Photoperiod during the post-inoculation stage was more important than the stage of plant development and degree of plant vigor that had resulted from the pre-inoculation photoperiod. Additional bean germplasm known to exhibit a differential response to $X c p$ under low and high latitudes, such as Pinto 'UI 114' (Arnaud-Santana et al., 1993), needs to be tested in a similar manner as described for 'PC-50' to confirm these results.

The mechanism of action of photoperiod on plant reaction to $X c p$ is unknown. Germplasm susceptible to $X c p$ in the tropics may show less common blight disease at higher latitudes. The latter response may be due to a physiological response of the plants under the long days of higher latitudes, which makes them less susceptible to the pathogen. This response has implications for bean breeders. However, this apparently resistant germplasm would not transmit genes for resistance to adapted susceptible beans developed in higher latitudes (unpublished, D.P.C.). Commonblight-resistant bean lines developed in temperate regions (Coyne and Schuster, 1983) expressed susceptibility to $X c p$ in the tropics (Webster et al., 1983) but transmitted genes for resistance to common blight when crossed to susceptible tropically adapted bean lines (S. Singh, Centro Internacional de Agricultura Tropical, Cali, Colombia; personal communi- cation). These results indicate that if a breeder did not know the influence of photoperiod on the reaction of bean germplasm to $X c p$, then in one situation germplasm may not be used in breeding where it should have been used. In another case, germplasm might be used where it would not be useful in transmitting resistance to progeny.

\section{Literature Cited}

Aggour, A.R., D.P. Coyne, and A.K. Vidaver. 1989. Comparison of leaf and pod disease reactions of beans (Phaseolus vulgaris L.) inoculated by different methods with strains of Xanthomonas campestris pv. phaseoli (Smith) Dye. Euphytica 43:143-152.

Andrus, C.F. 1948. A method of testing beans for resistance to common blights. Phytopathology 38:757-759.

Arnaud-Santana, E., D.P. Coyne, J.S. Beaver, and H.Z. Zaiter. 1993. Effect of photoperiod and temperature on common blight disease of common beans (Phaseolus vulgaris L.). Euphytica 66:211-216.

Claflin, L.F., A.K. Vidaver, and M. Sasser. 1987. MXP, a semi-selective medium for Xanthomonas campestris pv. phaseoli. Phytopathology 77:730-734.

Coyne, D.P. and M.L. Schuster. 1983. Genetics of and breeding for resistance to bacterial pathogens in vegetable crops. HortScience 18:30-36.

Hedges, F. 1928. Bacterial diseases of beans in some western commercial seed-growing and canning areas of southern trucking sections in 1927 and 1928. U.S. Bur. Plant Ind., Plant Dis. Rptr. $12: 121-122$.

McElroy, J.B. 1985. Breeding dry beans, Phaseolus vulgaris $\mathrm{L}$., for common bacterial blight resistance derived from Phaseolus acutifolius A. Gray. PhD Diss., Cornell Univ., Ithaca, N.Y.

Mohan, S.T. 1981. Breeding dry beans (Phaseolus vulgaris $\mathrm{L}$.) for common bacterial blight resistance: Relation of "days to flowering" to blight reaction. Turrialba 3:109-112.

Pastor-Corrales, M.A., S.E. Beebe, and F.J. Correa. 1981. Comparing two inoculation techniques for evaluating resistance in beans to Xanthomonas campestris pv. phaseoli, p. 493-503. In: J.Carlos and P. Gwin (eds.). Proc. Fifth Intl. Conf. Plant Pathol. Centro Internacional de Agricultura Tropical, Cali, Colombia.

SAS Institute. 1982. SAS user's guide: Statistics. SAS Institute, Cary, N.C.

Webster, D.M., S.R. Temple, and G.E. Galvez. 1983. Expression of resistance to Xanthomonas campestris pv. phaseoli in Phaseolus vulgaris under tropical conditions. Plant Dis. 67:394-396.

Yoshii, K. 1980. Common and fuscous blights, p. 155-172. In: H.F. Schwartz and G.E. Galvez (eds). Bean production problems. Centro Intl. de Agricultura Tropical, Cali, Colombia. 